\title{
How treatment, storm events and changed climate affect productivity of temperate forests in SW Germany
}

\author{
Jürgen Zell ${ }^{1} \cdot$ Marc Hanewinkel $^{2}$
}

Received: 5 May 2014/Accepted: 23 February 2015/Published online: 13 March 2015

(C) Springer-Verlag Berlin Heidelberg 2015

\begin{abstract}
The impact of heavy storm events, changed climate and treatment on the productivity of temperate forests was investigated for three representative stands in Southwest Germany. The simulation experiment was conducted on a Norway spruce, a mixed and a Douglas-fir stand. We applied a business-as-usual scheme (BAU), further a storm adapted management (SAM) and an early reduction in the tree density (BFB6). Further, we investigated the effects of two different climates, a current and a climate change scenario based on the A1B emissions with a HeadCM3 model chain. Simulations were run by the core functions of a single-tree growth simulator, with an empirical storm risk model, enabling to predict single-tree probabilities of being damaged. Further growing conditions were changed by modelling site index as a function of climate. The simulations were run over a period from 2010 to 2500 , and we investigated standing and harvested volume and net present value (NPV). Results show that storm frequency has a major impact on all output variables, followed by treatment. For the Douglas-fir stand, treatment is even more important for mean harvested volume, while it does not play a major role in the mixed stand. Compared with storm frequency and treatment, change in precipitation and temperature is less influential. There is a clear
\end{abstract}

Jürgen Zell

juergen.zell@wsl.ch

Marc Hanewinkel

marc.hanewinkel@ife.uni-freiburg.de

1 Swiss Federal Institute for Forest, Snow and Landscape Research (WSL), Zürcherstr. 111, 8903 Birmensdorf, Switzerland

2 Chair of Forestry Economics and Forest Planning, University of Freiburg, Tennenbacherstr. 4, 79106 Freiburg, Germany negative climate change effect on harvest levels for the spruce and mixed stand, while Douglas fir shows a distinct positive reaction. BFB6 shows the highest harvested and standing volume for both coniferous stands, but lower NPVs due to cutting of premature timber. BAU displays the best performance for NPV, while SAM yields the worst results for harvested and mean standing timber as well as for NPV. Assumptions and limitations of the study are discussed mainly referring to the long simulation period, and it is concluded that before implementing extreme strategies-like SAM - with effects similar to those of the disturbances, a forward-looking adaptive management should be considered.

Keywords Forest growth $\cdot$ Single-tree simulator $\cdot$ Storm events

\section{Introduction}

Climate change is affecting European forests in many ways. A projected change in temperature and precipitation in the next decades (Knutti and Sedlacek 2013) is expected to have an impact on productivity (Reyer et al. 2014) as well as the distribution and mortality (Allen et al. 2010) of major tree species in Europe.

Besides, gradual changes in temperature and precipitation disturbances and specifically extreme events are expected to be major drivers of a change in the growth conditions for European forests. In addition to fire and increased drought and heat (Ciais et al. 2005), mainly storm events have major impacts of the forest cover in Europe. Nabuurs et al. (2013) and Schelhaas et al. (2003) found that storms account for more than $50 \%$ of the observed damage to forests in Europe. Related to storms are 
follow-up damages such as bark beetle outbreaks (Temperli et al. 2013a, Stadelmann et al. 2014).

However, there are distinct differences of impacts of climate change on forests in different ecoregions of Europe. For productivity, a multitude of studies (e.g. Reyer et al. 2014) have shown that-depending on the investigated tree species-productivity increases in Northern Europe, increases or decreases in Central Europe and decreases in Southern Europe. According to Reyer et al. (2014), the productivity of Scots pine and Norway spruce, mostly located in central and northern Europe, increases, while the productivity of European beech and oak in southern regions decreases.

Albert and Schmidt (2010) show that under an A1B scenario, site index for Norway spruce decreases along a gradient of decreasing precipitation in Lower Saxony (North Germany), while the productivity of beech may increase with a temperature increase in higher altitudes. For temperate forests of Southwest Germany, Nothdurft et al. (2012) show that under two climate scenarios the site index of major tree species would be decreased in lowland areas and may increase in mountainous regions.

However, these findings do not take into account the impact of disturbances. Here, we have to consider that major drivers such as wildfire, windthrow and insect outbreaks are climate sensitive and are thus likely to be influenced by climatic change. Observations by Seidl et al. (2011) across Europe show that in recent decades, forest disturbance regimes have intensified decidedly, resulting in a strong increase in damage from wind, bark beetles and wildfires. However, they reveal that from the 1950s to 2000 , forest change (i.e. promoting productive conifers and increasing standing timber volume) contributed in the same order of magnitude as climate change to the increase in disturbance damage. Climate change was the main driver of the increase in fire damage, while changes in forest extent, structure and composition particularly affected the variation in wind and bark beetle damage (Seidl et al. 2011: 2842). In addition to that, Seidl and Blennow (2012) show that storms can have a pervasive negative impact on the increment of forests in the years after the storm.

While fire and drought play a most important role in the Mediterranean area, an increasing risk of disturbances through storms and insects can be observed in the temperate and Atlantic forests of Central and Western Europe (Gardiner et al. 2011). In order to adapt forests to climate change impacts, several options are available: Bolte et al. (2009) distinguish between three general adaptation strategies for European forests to a potentially difficult climatic future: (1) conservation of forest structures, (2) active adaptation and (3) passive adaptation. The conservation of forest structures assumes low adverse impacts of climate change, high stand resistance to climatic stress and high chances for success that silvicultural interventions will improve the stability. Passive adaptation means to give up management interventions and to use successional dynamics and natural species migration. Both strategies are only promising if severe climate scenarios do not occur or for forests with low economic importance. For intensively managed forests in Europe, active adaptation seems to be the most appropriate strategy, especially under stronger climate scenarios to be the likely future.

\section{Goal of the investigation}

We examined how the productivity in terms of timber production and economic output of temperate forest types are affected by an expected change in climate, different frequencies of heavy storm events under different management strategies. In detail:

1. How do different frequencies of a winter storm of the type "Lothar" affect different types of temperate forests?

2. How does an expected increase in temperature and a decrease in precipitation in the vegetation period under a moderate climate change affect productivity of these forests?

3. Can strategies that try to adapt these forests to the changed conditions through a limitation of the dominant height or an early reduction in the tree density to concentrate growth on few crop trees mitigate the expected impacts and how do these strategies perform compared to a business as usual?

4. How are the effects of the different impacts compared to each other for the different stand types and observed variables? Can we find interactions among them?

\section{Materials and methods}

\section{The case study}

The case study is located at the western edge of the Northern Black Forest of Southwest Germany, in an elevation between 250 and $1050 \mathrm{~m}$ above sea level (asl). Under the climatic conditions in the case-study area, a mixed European beech (Fagus silvatica L.) forest would develop naturally, with oaks (Quercus spp.) increasing in proportion towards lower elevations and silver fir (Abies alba Mill.) and Norway spruce (Picea abies (L.) Karst) towards higher elevations. Today, due to massive human influence, even-aged pure spruce stands are dominating in the higher regions (800-1050 $\mathrm{m}$ asl), while in the lower $(<500 \mathrm{~m})$ and middle parts $(500-800 \mathrm{~m}$ asl $)$ a broad mixture of stands can be found ranging from mixed Norway 
spruce-silver fir forests with intermixed European beech and Douglas fir (Pseudotsuga menziesii (Mirbel) Franco var. menziesii), mostly on dry sites (Temperli et al. 2012).

\section{Generation of the initial stands}

Three different stand types were used to represent a typical situation in the Black Forest. For better comparison, the stands started with the same initial age class (10-20 years old). The spruce stand has a share of $90 \%$ Norway spruce that is dominating European beech; it is located at a higher altitude of $919 \mathrm{~m}$ asl. Starting site indices (dominant tree height at age 100) are 36 and $28 \mathrm{~m}$, respectively. It is representative for the classical management of spruce dominated higher elevations. The second stand is a mixture of silver fir, Norway spruce and European beech with equal shares; it is located in the lower part $(380 \mathrm{~m}$ asl $)$ and represents a forest with a high recreational value due to its vicinity to the urban areas in the region. Owing to the mixture and the limited share of vulnerable species such as Norway spruce, this stand is assumed to be more stable against bark beetle outbreaks and heavy storm events (Schmidt et al. 2010). The tree species have fairly good starting site indices with 41,42 and $30 \mathrm{~m}$, respectively. The third stand type is dominated by Douglas fir, with a $30 \%$ admixture of European beech. It is located in the middle part (623 m asl) of the area with starting site indices of 44 and $32 \mathrm{~m}$. It represents a modern version of the productive forests.

To initialize the diameter distribution, a model-based approach was used. We calculated Weibull parameters for the distributions based on high-resolution forest enterprise inventory data ("Betriebsinventur"-BI, cf. Nothdurft et al. 2012) of Baden-Württemberg. Further, the shares of the tree species over the diameter classes change and reflect the dominance of the species (see Fig. 1). More details on this procedure can be found in (Temperli et al. 2012), specifically under the third type of initialization ("simulated").

\section{Climate data and scenarios}

We used the output of the HadRM3Q0/HadCM3Q0 (Collins et al. 2006) model output of the Hadley Centre Climate Prediction and Research model (HCCR) for the IPCC AR4 A1B emission scenario for the period 2081-2500 as given in Temperli et al. (2013b: Table 1) and compared it with current climate (CU 1990-2000). According to this model, mean temperature (year) is projected to increase by 1.53 (2015-2095) up to $3.39^{\circ} \mathrm{C}(2400-2495)$ in our region, while precipitation per year increases slightly (see Table 1), compared with CU. However, summer precipitation decreases by almost $18 \%$ from 573 to $473 \mathrm{~mm}$.

\section{The simulator}

Implementing an empirical storm risk model in the simulator

For the simulations, we used the single-tree growth simulator BWinPro and transcribed the core of the simulator into the statistical software R (R Core Team 2009). The core growth functions and processes are described in the handbook of BWinPro, including the parameters (Nagel 1997). Where possible, we used new parameters based on long-term observations form the Black Forest (Albrecht 2009). Thus, all relevant processes for the simulation of our initial forest stands (ingrowth, growth and mortality) were written as functions in R. This allowed some flexibility regarding the control of the simulation of detailed adaptation strategies.

Further, we linked the simulator to an empirical storm risk model (Schmidt et al. 2010). The model, a generalized additive model (GAM, Wood 2006), is based on data of the storm "Lothar" in 1999. It predicts probabilities of single trees to be damaged by such a storm, given a tree group, tree height and diameter. Further, it is terrain sensitive as it includes a modified Topex-to-distance index (Mitchell
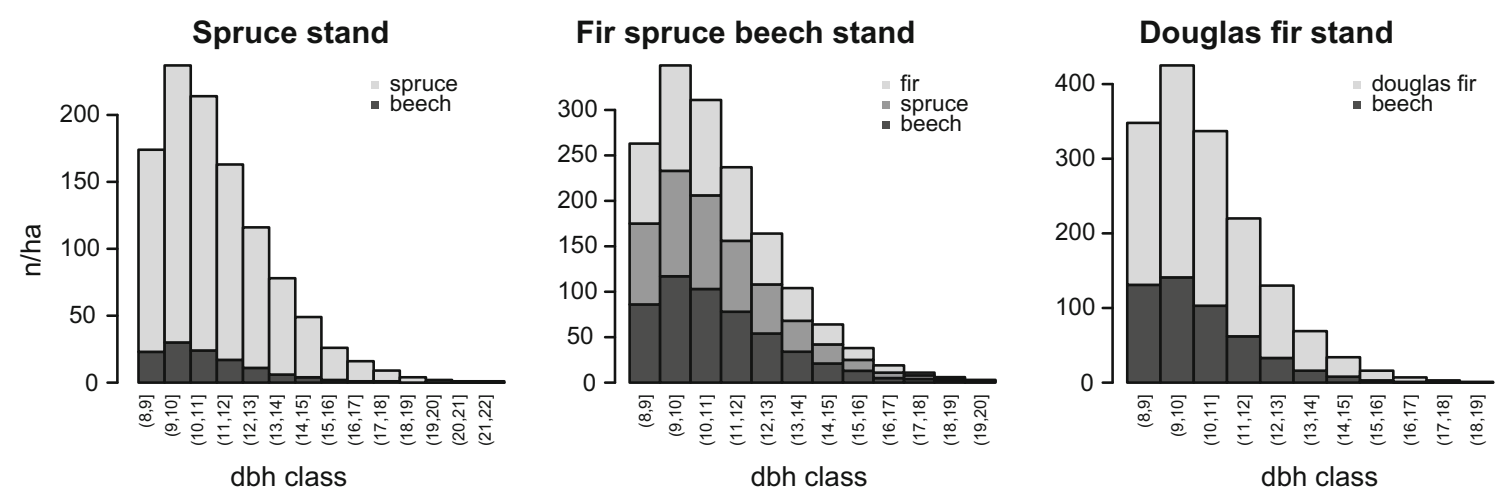

Fig. 1 Simulated initial stands with dbh-dominance for the leading species 
Table 1 Projected climate, as difference to current climate (CU)

\begin{tabular}{lccccc}
\hline & $2015-2095$ & $2100-2195$ & $2200-2295$ & $2300-2395$ & $2400-2495$ \\
\hline$\Delta$ Temp., year $\left({ }^{\circ} \mathrm{C}\right)$ & 1.53 & 3.30 & 3.20 & 3.14 & 3.39 \\
$\Delta$ Prec., year $(\mathrm{mm})$ & 69.24 & 40.70 & 79.35 & 77.40 & 65.05 \\
\hline
\end{tabular}

et al. 2001) that reflects exposure and main wind direction. We applied the model with stand-specific exposures for our model stands in the centre region of a storm. The exposures are typical in the sense that they are open to W-SW direction and hence have high storm vulnerability. On the single-tree level, the predicted probabilities were compared with a uniform random number. If the expected probability exceeded the random number, the tree was marked as being damaged by storm. In the same way, the occurrence of a storm was stochastically modelled, in order to investigate different storm frequencies.

\section{The effect of climate change on growth}

Based on National Forest Inventory (NFI) data in Germany, a site index model was calibrated. The method is similar to the one used in Nothdurft et al. (2012), but we concentrated on NFI data in Germany with a much lower resolution; hence, we did not find spatial autocorrelation. Basically, we used age $(t)$ and height $[h(t)]$ observations of a broad statistical data basis (the NFI) and fitted a growth curve [Sloboda's (1971) height growth function] with three parameters to the height increments (Eq. 1).

$\frac{\mathrm{d} h(t)}{\mathrm{d} t}=\beta \frac{h(t)}{t^{\propto}} \ln \left(\frac{65^{\gamma}}{h(t)}\right)$

Since the NFI data cover a broad range in space but include only two time steps, we replaced time by space in the fitting procedure. This allowed calculating single-treewise heights at the given age 100, which is the site index. Site index was then further explained by mean annual temperature, annual precipitation sum, tree species, stand age and height above sea level. The effect of temperature was formulated by a polynomial of degree two, both variables being significant and hence showing some optimality over temperature (see Fig. 2, left panel). The effect of precipitation was more complex and showed less effect size (Fig. 2, right panel). For the modelling, we used the library mgcv in R according to Wood (2006), which automatically determines the optimal smoothness of the nonparametric kernel functions via generalized crossvalidation (right panel in Fig. 2). Precipitation further showed a clear negative interaction with temperature, since temperature is usually negatively correlated with precipitation. The full model has the following form:

$g($ SiteIndex $)=X \beta+f_{1}($ Prec $)+f_{2}($ StandAge $)$
In Eq. 2, $X$ is the model matrix, containing the contrasts for the tree species, further temperature, temperature squared, temperature times precipitation, the interactions between tree species and temperature, the interactions between tree species and precipitation and further height above sea level. $\beta$ is the fixed parameter to be estimated, $g()$ is the link function (the natural logarithm), and $f_{1,2}()$ are smooth functions.

\section{The management strategies}

We used three different management strategies that were kept constant over the whole duration of the simulation: First, we applied business as usual (BAU), which is a future crop tree selection approach, where trees that should form the final stand are selected and are released through thinning operations. The number of crop trees depends on stand type. After reaching a tree-specific target diameter $(60 \mathrm{~cm}$ for beech, fir, spruce, $80 \mathrm{~cm}$ for Douglas fir), the crop trees are harvested over an extended period of time following species-specific target diameters, enabling new ingrowth trees (natural regeneration) for the next generation. This extended time depends on the top height in the stand, and the final harvest is prolonged as long as the top height is larger as $75 \%$ of the site index. In addition to that, a storm adaptive management (SAM) strategy was implemented, which is based on the idea that storm risk increases with tree height (cf. Schmidt et al. 2010). Hence, final felling of crop trees was defined by their tree height and not on their diameter $(30 \mathrm{~m}$ for Douglas fir and beech, $25 \mathrm{~m}$ for spruce). A third scheme was based on a suggestion of the local practitioners: crop trees were selected, and after a branch-free bole of the tree of $6 \mathrm{~m}$ (BFB6) was reached, all remaining competitors were removed at once to accelerate growth and increase the stability through improved $\mathrm{h} / \mathrm{d}$ ratios of the remaining crop trees. Like in the BAU scheme, the crop trees were harvested following target diameter prescriptions.

\section{Investigated variables}

In our analysis, we concentrated on the sum of removed and standing volumes and the net present value (NPV) in the different time steps. With the adopted interest rate of $2 \%$, the value of the final stand that should normally be part of the NPV is negligible. We thus focused on the value 
Predicted effects of Site-Index model

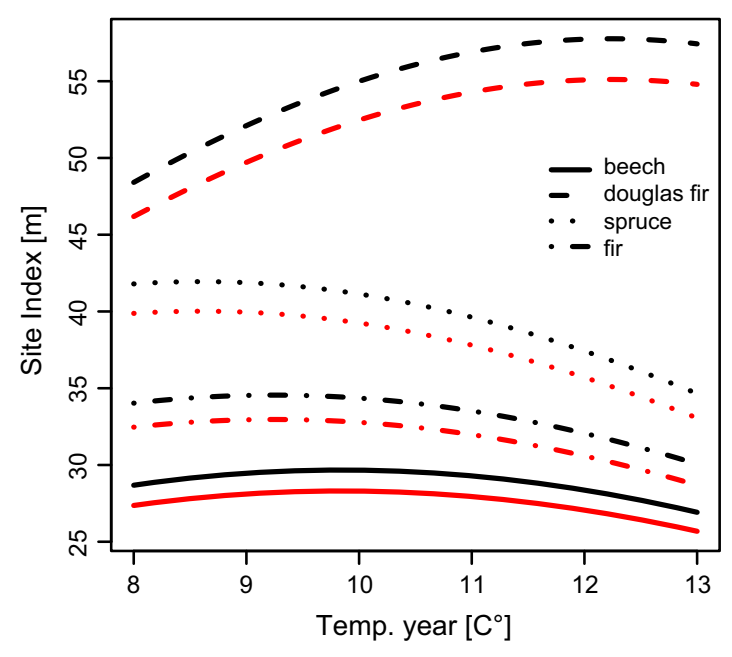

Fig. 2 Predicted effects of the site index model, keeping all other predictor variables constant. Left panel quadratic effect of mean annual temperature on estimated site index and right panel

of the initial stand and the removed volume for the calculation of the NPV (Eq. 3).

$\mathrm{NPV}(i, N)=\sum_{t=0}^{N} \frac{R_{t}}{(1+i)^{t}}$

where NPV $=$ net present value, $N=$ last year of investigation, $i=$ interest rate and $R_{t}=$ net revenue of harvest at time $t$ in the future.

We differentiated between regular and storm-damaged harvesting. Based on results of an investigation after the storm "Lothar" (Odenthal-Kahabka 2005), we assume that after each storm event, $70 \%$ of the storm-damaged volume was effectively harvested, with a reduction of $50 \%$ for net revenue of the salvage cuts. We calculated revenues net of harvesting costs per $\mathrm{m}^{3}$ for the different tree species as a function of the diameter at breast height dbh (see Fig. 3) according to Zell (2008).

\section{Scenarios}

For our simulations, we used a time frame from 2010 until 2500 in 5-year steps. Although this simulation period is unusually long for the application of empirical growth models, as the uncertainty of the predictions increases with time, we chose this long period to be able to simulate the effects of extreme storm events with low frequencies, i.e. a heavy storm with a return period of more than 100 years. Similar to applying a process-based model, we simulated into a long-lasting state near to equilibrium and thus capture situations after a storm where the complete structure and composition of the stand including the dominant tree

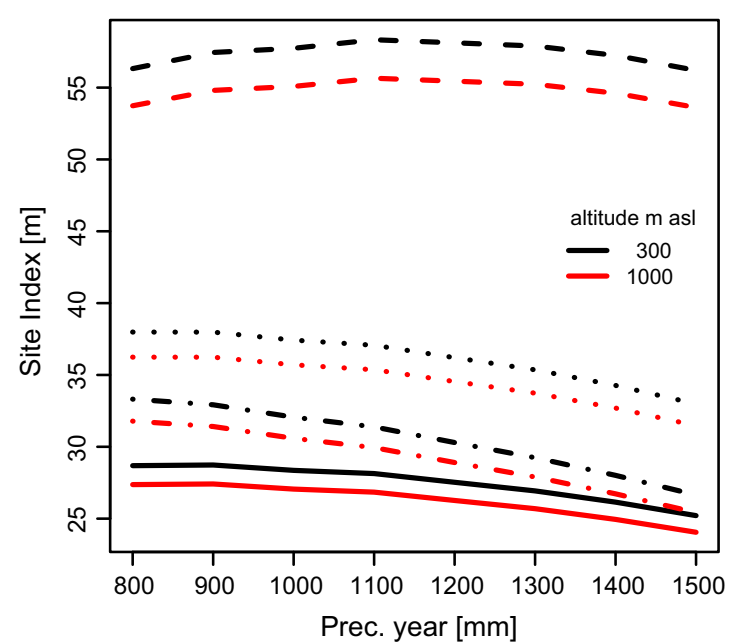

nonparametric smoothed effect of annual precipitation sum. Also a negative interaction between temperature and precipitation is included

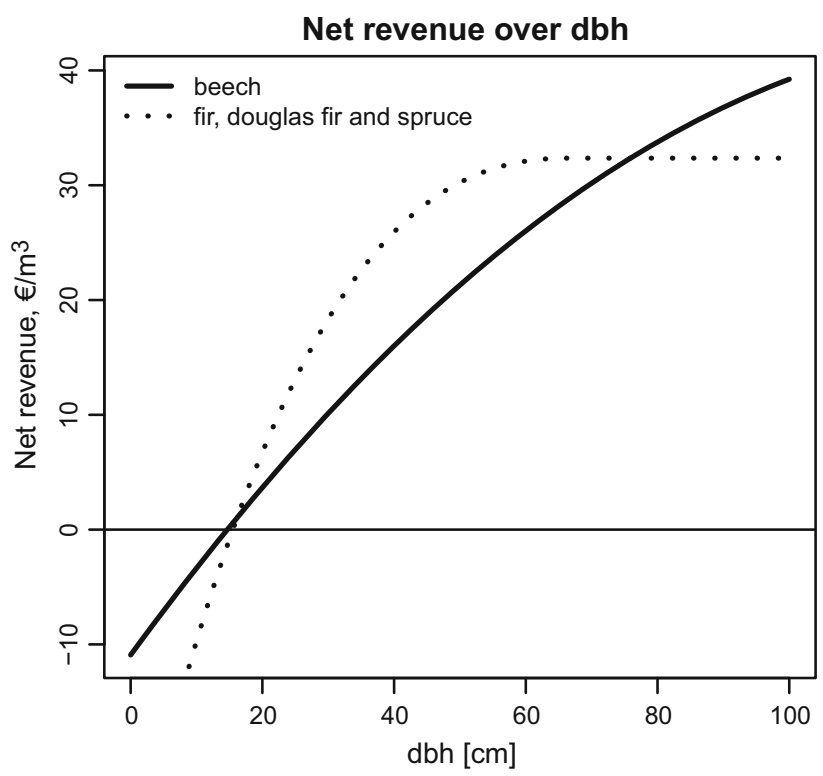

Fig. 3 Revenues net of harvesting costs $\left(€\right.$, per $\left.\mathrm{m}^{3}\right)$, per tree. Figure based on Zell (2008)

species will be changed. We discounted the resulting net revenues for timber using an interest rate of $2 \%$. To account for the uncertainty that the storm may hit different development phases of a forest stand, we repeated each scenario 25 times. A scenario is defined by a stand, a management prescription, a climate and a storm frequency in years (25 to infinity). As one scenario had a simulation time of $2 \mathrm{~min}$, we overall used around $105 \mathrm{~h}$ of CPU time for the total number of 3150 simulations. 


\section{Results and interpretation}

The results were analysed in the form of a classical analysis of variance (anova), including interaction terms between storm frequencies and treatments. The ANOVAs were separated for each stand type and variable of interest. Beside interactions, they contain main effects for climate, storm frequencies and treatments. Significance was only intermittently reported, since the number of repetitions may be arbitrarily large, and hence, more important for interpretation is the effect size.

\section{Impact of changed climate, treatment and storm frequencies on expected mean harvested volume}

Figure 4 gives an overview of the mean harvested volumes per stand, depending on the examined variables. On the $\mathrm{x}$-axis, the main effects are given, and on the y-axis, the resulting effect sizes can be found. In the case of the spruce stand (left panel in Fig. 4), the mean expected harvest yields $7.8 \mathrm{~m}^{3} / \mathrm{ha} / \mathrm{a}$ with a clearly negative effect of climate change $\left(-1.20 \mathrm{~m}^{3} / \mathrm{ha} / \mathrm{a}, p<2 \mathrm{e}-06\right)$. This effect is in the range of the effect size of the treatments. BAU is not optimal in terms of harvested volume, BFB6 results in slightly $(p=0.27)$ higher harvested volume. The strong effect of storms is not linear depending on storm frequencies and shows higher effects for frequencies between 25 and 75 years, compared with lower frequencies in the range of 100-150 years. This means that above a frequency of 100 years, the effects of storm are less dramatic as they are close to the regular rotation times of the stands and thus mimic the normal treatment. A higher frequency of the storm (below 100 years) has stronger effects on the productivity and is then rather considered to be a catastrophic event. A storm frequency of 25 years reduces the mean harvested volume by more than $40 \%$ to less than $5 \mathrm{~m}^{3} / \mathrm{ha} /$ a, which is below the productivity of the worst sites in the region.

In the case of the mixed stand (mid panel of Fig. 4), the effect of treatment is very small. Here, the mixture seems to outweigh the effects of the silvicultural interventions. Like in the spruce stand, a clear negative effect of climate change $\left(-1.05 \mathrm{~m}^{3} / \mathrm{ha} / \mathrm{a}, p<2 \mathrm{e}-06\right)$ is visible. The effect of storm is similar to the one of the spruce stands. The highest storm frequency reduces the harvested volume to a level below $3 \mathrm{~m}^{3} / \mathrm{ha} / \mathrm{a}$, which would strongly limit the potential for timber production.

Only the Douglas-fir stand (right panel of Fig. 4) shows a clear positive effect of climate change: HC shows a significantly higher mean harvested volume compared with the current climate with $+4.49 \mathrm{~m}^{3} / \mathrm{ha} / \mathrm{a}, \quad(p<2 \mathrm{e}-06)$. Only in this stand the effects of treatment even outweigh those of the different storm frequencies. Due to the limitation in the maximum height, the storm adapted management produces the lowest mean harvest volume that yields less than $50 \%$ of the strategy with early release of crop trees. The total storm effects are less severe compared with spruce or the mixed stand. Even a storm frequency of 25 years leads to a mean harvesting level of close to $10 \mathrm{~m}^{3} /$ ha/a.

Figure 5 shows the mean harvest levels and their interactions between storm frequencies and treatments, for both climates. The figure reveals that only in the mixed stand (fir, spruce, beech mid panel of Fig. 5) and under a
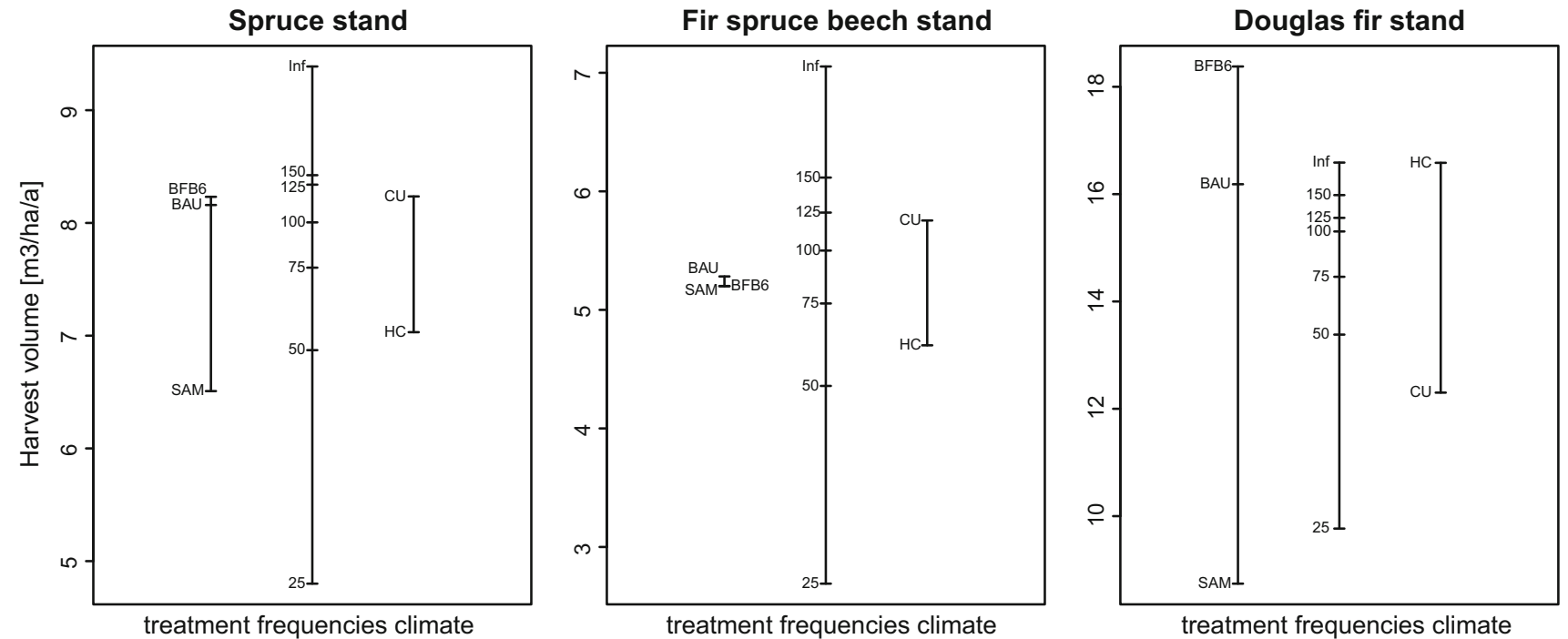

Fig. 4 Main effects on mean harvested volume (2010-2500) for the three initial stands (left spruce, middle: fir/spruce/beech, right Douglas fir). Treatments: BAU business as usual, SAM storm adaptive management, BFB6 early removal of competitors at $6 \mathrm{~m}$ of branchfree bole. Climate: $C U$ current climate, $H C$ climate change. Frequency: storm frequency in years 


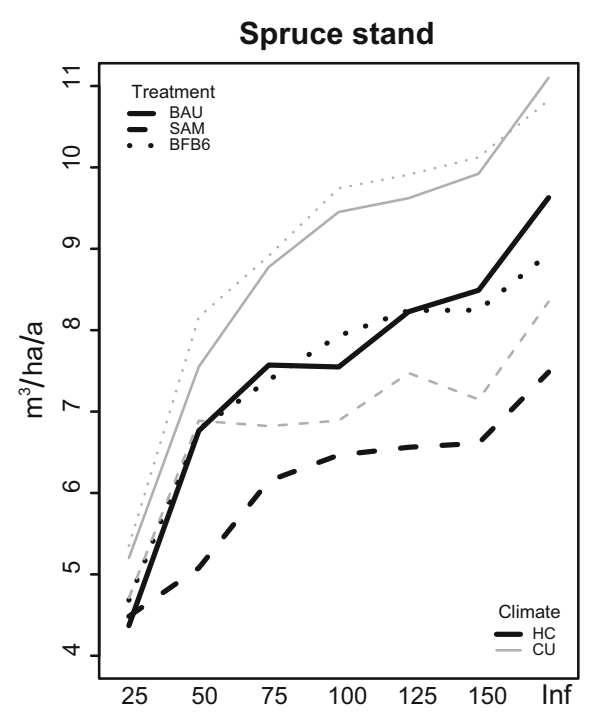

Fir spruce beech mixed stand

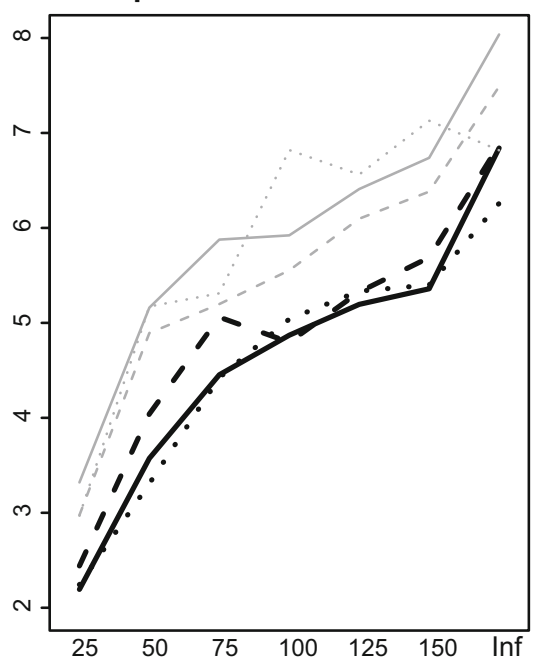

Douglas fir stand

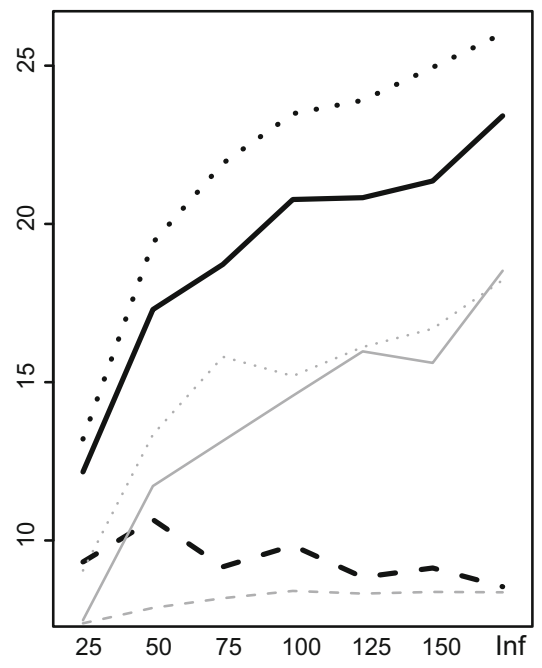

Fig. 5 Interaction between storm frequencies and treatments on mean harvest volume (2010-2500) over storm frequencies, grey lines current climate $(\mathrm{CU})$, bold lines changed climate (HC). Management scenarios: solid line business as usual (BAU). Dotted line branch-free bole at $6 \mathrm{~m}$ (BFB6) treatment (see explanation). Dashed line storm adaptive management (SAM) changed climate the SAM (dashed line) yields slightly higher harvest levels (up to a storm frequency of 75 years). The corresponding interaction term shows weak evidence $(p=0.053)$. This means that only for this stand type the SAM has a positive effect on harvest levels. This is not visible for the spruce or Douglas-fir stands where BFB6 (dotted line) or BAU (solid line) yields the highest harvest levels. The figure shows that for all scenarios, the mean harvesting level increases with decreasing storm frequency. However, SAM for the productive Douglas-fir stand type leads to distinctly lower harvestings volumes and even levels out the effect of increasing storm frequencies.

\section{Impact of CC, treatment and storm frequencies on standing volume}

Figure 6 shows how the different scenarios impact the mean standing volume during the simulation period. The general trends are similar to those of the harvesting volume. However, for the spruce stand, BAU is the best strategy (compared to BFB6), while for the mixed stand there is a visible influence of the management strategy that was not detectable for the harvested volume. For the Douglas-fir stand, the influence of the treatment is less distinct with a greater importance of the storm frequency and a smaller difference between BFB6 and BAU. The interactions (not shown here) are very similar to those shown in Fig. 5: the only visible effect of a SAM scheme can be detected for the mixed stand and the climate change scenario until a storm frequency of 125 years.

\section{Impact of CC, treatment and storm frequencies on NPV}

Figure 7 reveals that the storm frequencies have the strongest influence on the net present value compared with the treatments that stronger influence the harvested volume (Fig. 4). For the two coniferous stands, BAU is the most advantageous management option, while for the mixed stand SAM is slightly superior to BAU. The figure shows an opposite effect of the strategy BFB6 on NPV compared with the harvested volume. For all three stands, BFB6 yields the lowest NPV. This is an effect of the very early cuttings in this regime that include mainly small trees with rather low economic value. Due to the rather low interest rate that we applied, the timing of the cutting that would favour early interventions in terms of NPV is less important. Only for the mixed stand, the SAM shows a slight advantage compared with BAU.

The interactions between storm frequencies and treatments on NPV (Fig. 8) for the spruce stand show similar trends for the BAU treatment and the SAM; until a frequency of 100 years, their related contrasts are not significant $(p>0.1)$. For lower storm frequencies of 125 years onwards, the negative effect of SAM is significant $(p<0.01)$. Like in the case of harvested volume, only in the mixed stand SAM seems to outperform BAU under the climate change scenario. Here, the NPV is higher even until a storm frequency of 150 years (compared to only 75 years for the harvested volume), but this difference is not significant throughout the whole time range. For the Douglas-fir stand, BAU is clearly and significantly the best performing strategy for both current and changed climate. 


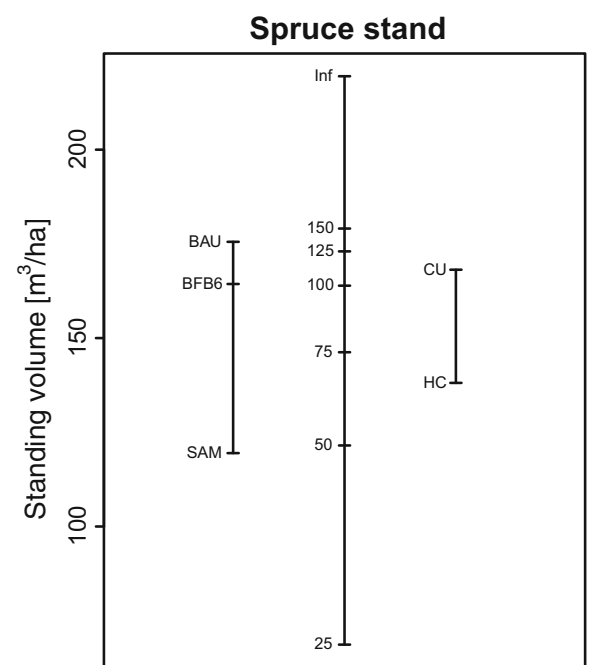

Treatment Frequencies Climate
Fir spruce beech stand

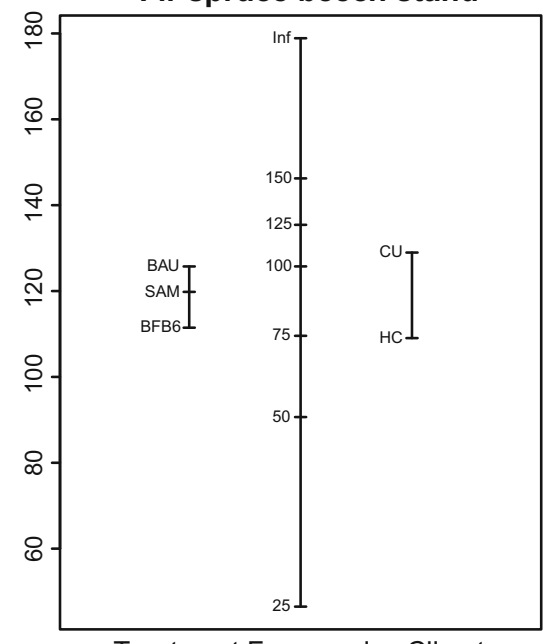

Treatment Frequencies Climate
Douglas fir stand

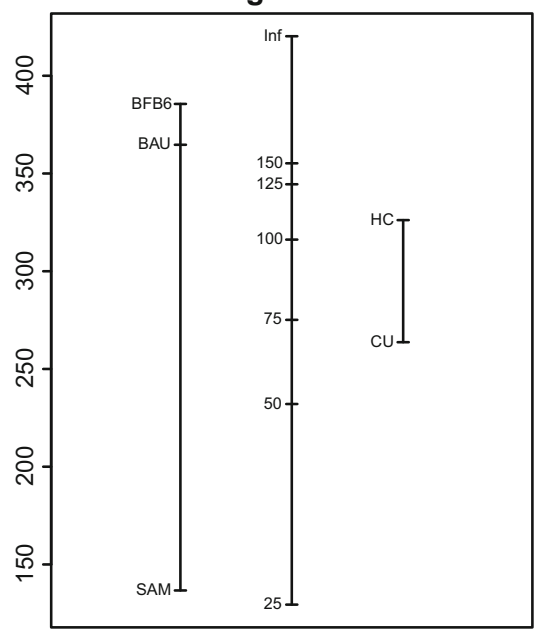

Treatment Frequencies Climate
Fig. 6 Main effects on mean standing volume (2010-2500) for the three initial stands (left spruce, middle: fir/spruce/beech, right Douglas fir). Treatments: $B A U$ business as usual, $S A M$ storm adaptive management, $B F B 6$ early removal of competitors at $6 \mathrm{~m}$ of branchfree bole. Climate: $C U$ current climate, $H C$ climate change. Frequency: storm frequency in years

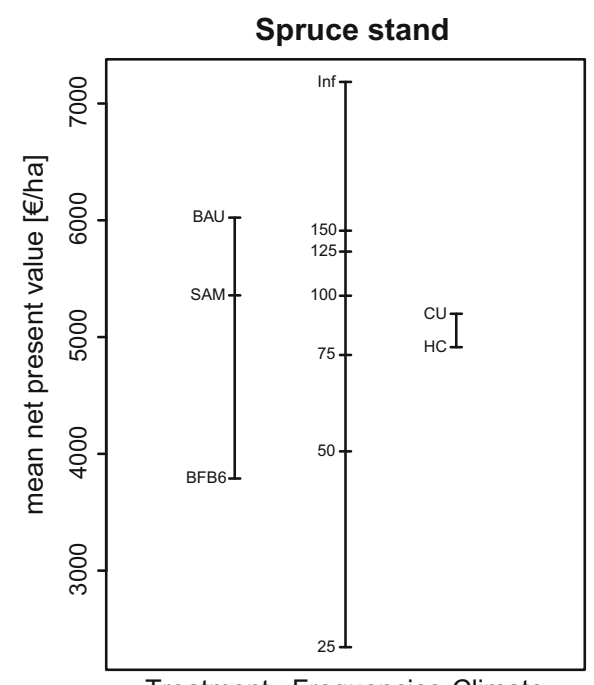

Treatment Frequencies Climate

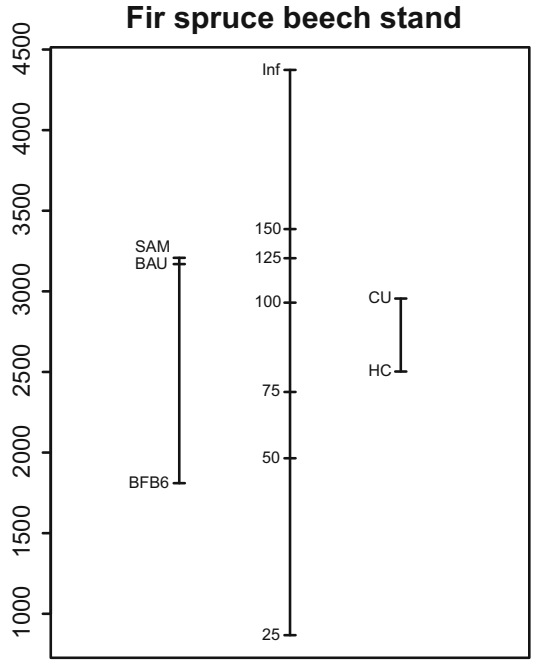

Treatment Frequencies Climate
Douglas fir stand

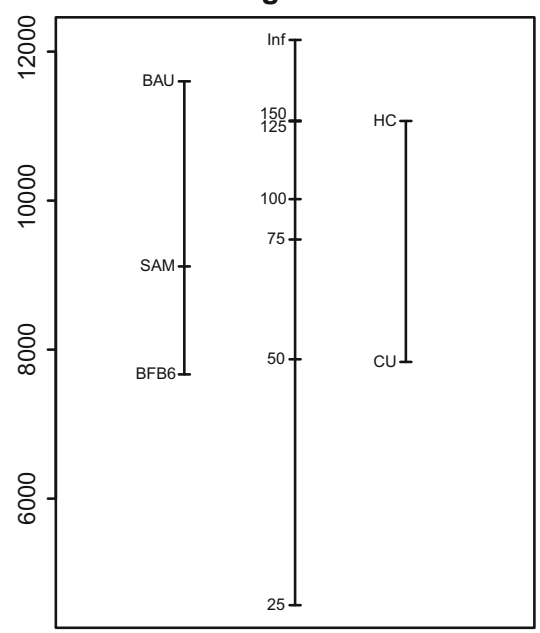

Treatment Frequencies Climate
Fig. 7 Main effects on net present value (NPV, 2010-2500) for the three initial stands (left spruce, middle: fir/spruce/beech, right Douglas fir). Treatments: $B A U$ business as usual, $S A M$ storm adaptive

\section{Discussion}

In our simulation study, we investigated the effect of treatment, extreme events and a changed climate on the productivity and their interactions of different forest types in temperate forests. Extreme events, in our case, a winter storm of the type "Lothar", were modelled as a stochastic process with different frequencies of occurrence. In our study, we were mostly interested in the strength of the effect of the different impacts on the productivity and less on a realistic depiction of the development of the stands management, BFB6 early removal of competitors at $6 \mathrm{~m}$ of branchfree bole. Climate: $C U$ current climate, $H C$ climate change. Frequency: storm frequency in years

that we simulated or an overall optimization of an adaptive management that we consider to be very difficult under the strong uncertainty of the impact of extreme events and climate change at the same time. We therefore restricted our analysis to few rather simple variables that are all related to timber production.

In order to be able to include extreme storm events with higher frequencies of more than 100 years, we extended our simulation period to almost 500 years and ran the simulations into a nearly equilibrium, which is unusually long at least for the application of an empirical growth 


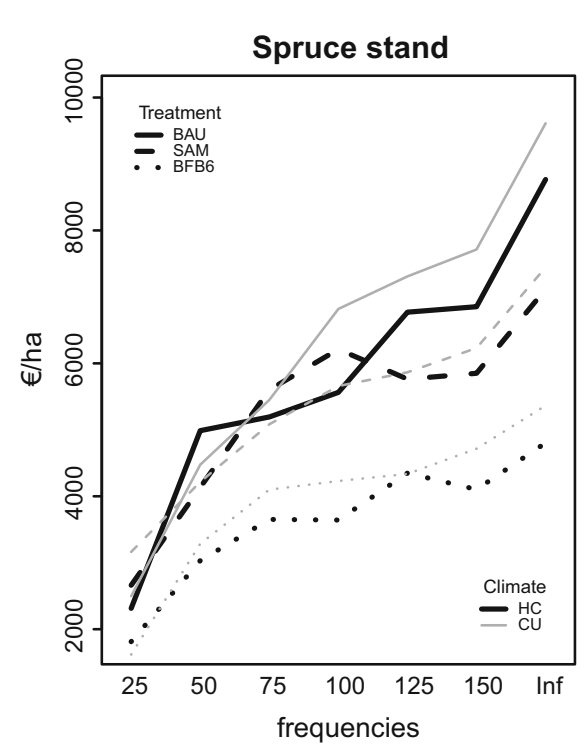

Fig. 8 Interaction between storm frequencies and treatments on net present value (2010-2500), over storm frequencies, grey lines current climate (CU), bold lines changed climate (HC). Management

model. However, we refrained from applying economic approaches such as the Faustmann model (Faustmann 1849) that draws on an eternal repetition of identical production cycles (rotation times), as it would have been impossible to combine this with the stochastic approach of including extreme storm events that we followed here. Applying a generalized Faustmann model as proposed by Chang (1998) or including risk in the standard model (Reed 1984) or Monte Carlo techniques to alter survival probabilities (Dieter 2001) may be first steps towards applying a classical land expectation value to such a research question.

Applying very long observation periods to financial variables is of course particularly critical as the uncertainty increases with time. The applied interest rate of $2 \%$ buffers some of the uncertainty. Higher interest rates would better cache the high uncertainties, but they are quite uncommon in these forests. The net present value that we generated is meant to be a condensed index combining output of timber production and standing volume. Comparing the different management regimes, this leads to the effect that the strategy with very early interventions yields high harvesting and standing volumes, but low net present values as most of the timber will be cut prematurely. The relation in value between diameter and net revenue (according to Fig. 3) stays constant in our simulation experiment, but would change, if the demand for different products or emerging new technologies will change in reality (e.g. Sohngen et al. 2007; Raunikar et al. 2010).

In our investigation, we only used one realization of a climate scenario - a rather tough one, with the HeadCM3 model chain (Hijmans et al. 2005). To properly account for

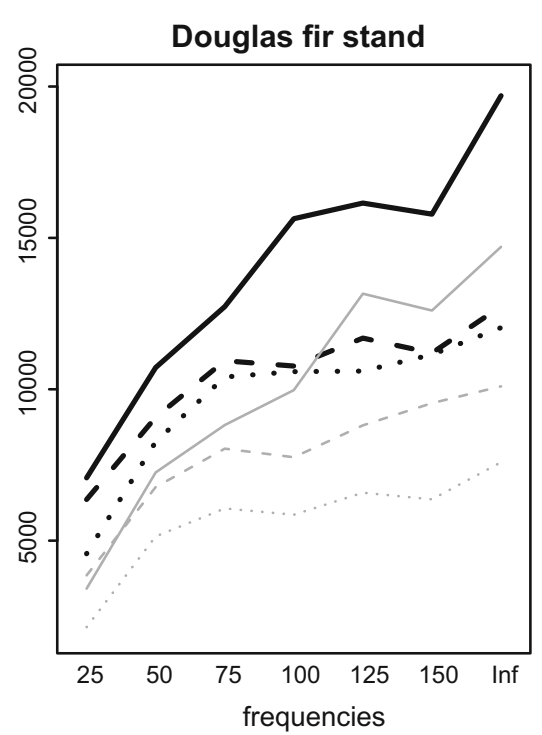

scenarios: solid line business as usual (BAU). Dotted line branchfree bole at $6 \mathrm{~m}$ (BFB6) treatment (see explanation). Dashed line storm adaptive management (SAM)

uncertainty related to climate scenarios, the application of several realizations of one scenario (Hanewinkel et al. 2013) or even multiple scenarios would be necessary. Here, we were mostly interested in the effect of a changed climate and not in the most realistic depiction a wide array of potential climates. Further, we do not provide for a transition phase between the current climate and the new climate as other investigations do (e.g. Kellomäki et al. 2008). Instead, we directly contrast the growth of the three stands of today's climate with the already changed climate in the future. To minimize high unrealistic fluctuations in the calculated site indices, we used the years 1990-2000 as reference, where some climate change has already taken place.

Our strategies that we applied to the different stands are kept constant. Therefore, we do not consider the behaviour of the decision-maker to be "trend adaptive" or even "forward-looking trend adaptive" as a decision-maker should behave in the ideal case. Using Bayesian updating and Dempster's rule of combination, Yousefpour et al. (2013) have shown that it can indeed be useful to use updated knowledge in decision-making for climate change. The result of our study was not designed to optimize adaptive management.

We have shown that treatment has an important effect on the productivity, compared, e.g., with the effect of the changed climate. The strong influence of management is in line with findings by Köhl et al. (2010) who revealed the influence of management as a main driving force for the effect of climate change on forests. Here, we show that extreme events and change in productivity under climate change may overwhelm this effect. Specifically with high 
frequencies of storms, effects of management are negligible.

A return frequency of 25 years may lead to an overall decrease in the productivity that makes economically oriented forestry difficult, except for fast-growing species such as Douglas fir that can be run on very short rotation times. However, here we have to admit that we simulated an extreme storm by choosing the centre of the storm with the highest reported wind speeds (Schmidt et al. 2010). This may also be the reason, why SAM is not really effective. Under lower wind speeds, this might be different. Technically, it would be possible to alter also the wind speeds, which inflates the variance of the output and also expands the number of possible scenarios. Hence, much more computing power would be needed to capture these problems.

In addition, we found that the effect of the treatment is very much stand type specific and it may also be an effect of the lack of other disturbances that we did not include. In our study, the mixed stands react much less on different treatments than the very productive pure coniferous stands. For most of the scenarios especially when taking into account economic aspects, BAU is still the preferable strategy. Neither increased mortality due to pests and insects or increased drought or its interaction are included in our simulation (e.g. Jönsson et al. 2007, 2009; Temperli et al. 2013a). From a multitude of studies, however (e.g. Seidl et al. 2008), we know that specifically a species such as Norway spruce will most suffer from this type of disturbances that are expected to increase under changing climatic conditions (Seidl et al. 2011). We also do not take into account growth reductions due to storm damage, an effect that has also been observed for Norway spruce (Seidl and Blennow 2012).

This investigation only contributes little to the question of which tree species should be planted to best adapt forests to climate change as we concentrate on economic and timber production-related ecosystem services, where fastgrowing species such as Norway spruce or Douglas fir have advantages. Temperli et al. (2012) have shown for the same types of temperate forests that, if multiple goods and services such as biodiversity and biomass are taken into account, mixed stands overall perform better than pure stands. Knoke et al. (2008) point at the necessity of taking into account multiple risks when comparing mixed to pure stands, specifically if decision-makers show a risk-averse behaviour.

Biome shifts have not been taken into account in our model. We thus assume that the species that we are dealing with will still be able to grow on our case-study sites under the assumed climate scenario. This may be realistic for Norway spruce in high elevations and for the mixed stands in lower elevations, and according to the latest species distribution models for the region (Hanewinkel et al. 2014), we have to be aware that we might lose a large part of the coniferous tree species under the given climate scenario. For Douglas fir, this is very difficult to evaluate, as there is no reliable biome shift model in the region.

\section{Conclusions}

Our simulation study reveals that beside storm frequency, the management strategy has a strong influence on the productivity of forests under a changed climate. Applying extreme treatments, like a limitation of the dominant height of the trees well below the production potential, or by very early reductions in the density of the stands by premature cutting of trees, leads to either a reduced harvesting volume or reduced net present value, mainly for pure stands of productive coniferous tree, but less for mixed stands. These strategies may then have a similar effect than the disturbance itself. Very high storm frequencies of 25 years may lead to framework conditions where an economically oriented forest management is not feasible any more as the harvested volume will be too low. As a consequence, forest management will have to focus on other ecosystem services such as biodiversity.

Acknowledgments This study was funded by MOTIVE project (models for adaptive forest management, Grant No. 226544). The project is supported by the European Commission under the Environment (including climate change) Theme of the 7th Framework Programme for Research and Technological Development. We also want to thank the two anonymous referees for their helpful and constructive comments.

\section{References}

Albert M, Schmidt M (2010) Climate-sensitive modelling of siteproductivity relationships for Norway spruce (Picea abies (L.) Karst.) and common beech (Fagus sylvatica L.). For Ecol Manag 259:739-749. doi:10.1016/j.foreco.2009.04.039

Albrecht A, Kohnle U, Nagel J (2009) Parametrisierung und Evaluierung von BWinPro für Baden-Württemberg anhand von waldwachstumskundlichen Versuchsflächendaten. Deutscher Verband Forstlicher Forschungsanstalten, Sektion Ertragskunde, Conference proceedings 2009 (in German). http://www.nw-fva. de/ nagel/SektionErtragskunde/band2010/Tag2010_02.pdf

Allen CD, Macalady AK, Chenchouni H, Bachelet D, McDowell N, Vennetier M, Kitzberger T, Rigling A, Breshears DD, Hogg EH, Gonzalez P, Fensham R, Zhang Z, Castro J, Demidova N, Lim J-H, Allard G, Running SW, Semerci A, Cobb N (2010) A global overview of drought and heat-induced tree mortality reveals emerging climate change risks for forests. For Ecol Manag 259:660-684. doi:10.1016/j.foreco.2009.09.001

Bolte A, Ammer C, Löf M, Madsen P, Nabuurs G-J, Schall P, Spathelf P, Rock J (2009) Adaptive forest management in central Europe: climate change impacts, strategies and integrative concept. Scand J For Res 24:473-482. doi:10.1080/ 02827580903418224 
Chang SJ (1998) A generalized Faustmann model for the determination of optimal harvest age. Can J For Res 28:652-659. doi:10. 1139/x98-017

Ciais P, Reichstein M, Viovy N, Granier A, Ogé J, Allard VA, Buchmann MN, Bernhofer Carrara A, Chevallier F, De Noblet N, Friend A, Friedlingstein P, Grünwald T, Heinesch B, Keronen P, Knohl A, Krinner G, Loustau D, Manca G, Matteucci G, Miglietta F, Ourcival J, Papale D, Pilegaard K, Rambal S, Seufert G, Soussana J, Sanz M, Schulze ED, Vesala T, Valentini R (2005) Europe-wide reduction in primary productivity caused by the heat and drought in 2003. Nature 437:529-533. doi:10. 1038/nature03972

Collins M, Booth B, Harris G, Murphy J, Sexton D (2006) Towards quantifying uncertainty in transient climate change. Clim Dyn 27:127-147. doi:10.1007/s00382-006-0121-0

Dieter M (2001) Land expectation values for spruce and beech calculated with Monte Carlo modelling techniques. For Policy Econ 2:157-166. doi:10.1016/S1389-9341(01)00045-4

Faustmann M (1849) Calculation of the value which forest land and immature stands possess for forestry. J For Econ 1(1995):7-44 (Reprinted from Commonwealth Forestry Institute of Oxford, Institute Paper 42, 1968)

Gardiner B, Blennow K, Carnus J-M, Fleischer P, Ingemarson F, Landmann G, Lindner M, Marzano M, Nicoll B, Orazio C, Peyron JL, Reviron M-P, Schelhaas M-J, Schuck A, Spielmann M, Usbeck T (2011) Destructive storms in European forestspast and forthcoming impacts. European Forest Institute, Atlantic European Regional Office-EFIATLANTIC. Final Report to European Commission, DG Environment

Hanewinkel M, Cullmann D, Schelhaas M-J, Nabuurs G-J, Zimmermann NE (2013) Climate change may cause severe loss in economic value of European forestland. Nat Clim Change 3:204-207. doi:10.1038/nclimate1687

Hanewinkel M, Cullmann DA, Michiels H-G, Kändler G (2014) Converting probabilistic tree species range shift projections into meaningful classes for management. J Environ Manag 134:153-165. doi:10.1016/j.jenvman.2014.01.010

Hijmans R, Cameron SE, Parra J, Jones P, Jarvis A (2005) Very high resolution interpolated climate surfaces for global land areas. Int J Climatol 25:1965-1978. doi:10.1002/joc.1276

Jönsson AM, Harding S, Bärring L, Ravn HP (2007) Impact of climate change on the population dynamics of Ips typographus in southern Sweden. Agric For Meteorol 146:70-81. doi:10. 1016/j.agrformet.2007.05.006

Jönsson AM, Appelberg G, Harding S, Bärring L (2009) Spatiotemporal impact of climate change on the activity and voltinism of the spruce bark beetle, Ips typographus. Glob Change Biol 15:486-499. doi:10.1111/j.1365-2486.2008.01742.x

Kellomäki S, Peltola H, Nuutinen T, Korhonen KT, Strandman H (2008) Sensitivity of managed boreal forests in Finland to climate change, with implications for adaptive management. Phil Trans R Soc Lond B 363:2339-2349. doi:10.1098/rstb.2007.2204

Knoke T, Ammer C, Stimm B, Mosandl R (2008) Admixing broadleaved to coniferous tree species: a review on yield, ecological stability and economics. Eur J For Res 127:89-101. doi:10.1007/s10342-007-0186-2

Knutti R, Sedlacek J (2013) Robustness and uncertainties in the new CMIP5 climate model projections. Nat Clim Change 3:369-373. doi:10.1038/nclimate 1716

Köhl M, Hildebrandt R, Olschowsky K, Köhler R, Rötzer T, Mette T, Pretzsch H, Köthke M, Dieter M, Mengistu A, Makeschin F, Kentner B (2010) Combating the effects of climatic change on forests by mitigation strategies. Carbon Balance Manag 5:8. doi:10.1186/1750-0680-5-8

Mitchell S, Hailemariam T, Kulis Y (2001) Empirical modeling of cutblock edge windthrow risk on Vancouver Island, Canada, using stand level information. For Ecol Manag 154:117-130. doi:10.1016/S0378-1127(00)00620-4

Nabuurs GJ, Lindner M, Verkerk PJ, Gunia K, Deda P, Michalak R, Grassi G (2013) First signs of carbon sink saturation in European forest biomass. Nat Clim Change 3:792-796. doi:10.1038/ nclimate 1853

Nagel J (1997) BWIN program for stand analysis and prognosis. User's manual for version 3.0, Niedersächsische Forstliche Versuchsanstalt Göttingen, 44 pp (German)

Nothdurft A, Wolf T, Ringeler A, Böhner J, Saborowski J (2012) Spatio-temporal prediction of site index based on forest inventories and climate change scenarios. For Ecol Manag 279:97-111. doi:10.1016/j.foreco.2012.05.018

Odenthal-Kahabka J (2005) Fünf Jahre nach "Lothar" - Ergebnisse der Sturmschadensbewältigung im Kleinprivatwald (5-200 ha) Baden-Württemberg, Teil I. Der Waldwirt 32:13-16 (German)

R Core Team (2009) R: a language and environment for statistical computing. R Foundation for Statistical Computing, Vienna

Raunikar R, Buongiorno J, Turner J, Zhu S (2010) Global outlook for wood and forests with the bioenergy demand implied by scenarios of the Intergovernmental Panel on Climate Change. For Policy Econ 12:48-56. doi:10.1016/j.forpol.2009.09.013

Reed WJ (1984) The effects of the risk of fire on the optimal rotation of a forest. J Environ Econ Manag 11:180-190. doi:10.1016/ 0095-0696(84)90016-0

Reyer C, Lasch-Born P, Suckow F, Gutsch M, Murawski A, Pilz T (2014) Projections of regional changes in forest net primary productivity for different tree species in Europe driven by climate change and carbon dioxide. Ann For Sci 71:211-225. doi:10.1007/s13595-013-0306-8

Schelhaas MJ, Nabuurs G-J, Schuck A (2003) Natural disturbances in the European forests in the 19th and 20th centuries. Glob Change Biol 9:1620-1633. doi:10.1046/j.1365-2486.2003.00684.x

Schmidt M, Hanewinkel M, Kändler G, Kublin E, Kohnle U (2010) An inventory-based approach for modeling single tree storm damage-experiences with the winter storm 1999 in southwestern Germany. Can J For Res 40:1636-1652. doi:10.1139/X10099

Seidl R, Blennow K (2012) Pervasive growth reduction in Norway spruce forests following wind disturbance. PLoS ONE 7:e33301. doi:10.1371/journal.pone.0033301

Seidl R, Rammer W, Jäger D, Lexer MJ (2008) Impact of bark beetle (Ips typographus L.) disturbance on timber production and carbon sequestration in different management strategies under climate change. For Ecol Manag 256:209-220. doi:10.1016/j. foreco.2008.04.002

Seidl R, Schelhaas M-J, Lexer MJ (2011) Unraveling the drivers of intensifying forest disturbance regimes in Europe. Glob Change Biol 17:2842-2852. doi:10.1111/j.1365-2486.2011.02452.x

Sohngen B, Alig R, Solberg B (2007) The forest sector, climate change, and the global carbon cycle. The Ohio State University, Department of Agricultural, Environmental and Development Economics

Stadelmann G, Bugmann H, Wermelinger B, Bigler C (2014) Spatial interactions between storm damage and subsequent infestations by the European spruce bark beetle. For Ecol Manage 318:167-174. doi:10.1016/j.foreco.2014.01.022

Temperli C, Bugmann H, Elkin C (2012) Adaptive management for competing forest goods and services under climate change. Ecol Appl 22:2065-2077. doi:10.1890/12-0210.1

Temperli C, Bugmann H, Elkin C (2013a) Cross-scale interactions among bark beetles, climate change, and wind disturbances: a landscape modeling approach. Ecol Monogr 83:383-402. doi:10. $1890 / 12-1503.1$

Temperli C, Zell J, Bugmann H, Elkin C (2013b) Sensitivity of ecosystem goods and services projections of a forest landscape 
model to initialization data. Landsc Ecol 28:1337-1352. doi:10. 1007/s10980-013-9882-0

Wood SN (2006) Generalized additive models: an introduction with R. Chapman \& Hall/CRC, Boca Raton, p 391

Yousefpour R, Temperli C, Bugmann H, Elkin C, Hanewinkel M, Meilby H, Bredahl Jacobsen J, Thorsen BJ (2013) Updating beliefs and combining evidence in adaptive forest management under climate change: a case study of Norway spruce (Picea abies L. Karst) in the Black Forest, Germany. J Environ Manag 122:56-64. doi:10.1016/j.jenvman.2013.03.004

Zell J (2008) Methoden für die Ermittlung, Modellierung und Prognose der Kohlenstoffspeicherung in Wäldern auf Grundlage permanenter Grossrauminventuren. PhD-thesis, University of Freiburg, Freiburg (German). http://www.freidok.uni-freiburg. de/volltexte/5400/pdf/zell_diss.pdf 